OPEN ACCESS

Edited by:

Andrés Moya

University of Valencia, Spain

Reviewed by:

Daniel Martinez,

Imperial College London,

United Kingdom

Daniel A. Medina,

San Sebastián University, Chile

${ }^{*}$ Correspondence:

Rafael Azevedo Baraúna

rabarauna@ufpa.br

Specialty section: This article was submitted to

Evolutionary and Genomic

Microbiology

a section of the journal

Frontiers in Genetics

Received: 03 September 2020 Accepted: 17 December 2020 Published: 12 February 2021

Citation:

Conceição MVR, Costa SS, Schaan AP, Ribeiro-dos-Santos ÂKC,

Silva A, das Graças $D A$,

Schneider MPC and Baraúna RA

(2021) Amazonia Seasons Have an

Influence in the Composition of Bacterial Gut Microbiota of Mangrove

Oysters (Crassostrea gasar).

Front. Genet. 11:602608

doi: 10.3389/fgene.2020.602608

\section{Amazonia Seasons Have an Influence in the Composition of Bacterial Gut Microbiota of Mangrove Oysters (Crassostrea gasar)}

\author{
Marcos Vinícius Reis Conceição ${ }^{1,2}$, Sávio Souza Costa 1,2, Ana Paula Schaan ${ }^{3}$, \\ Ândrea Kely Campos Ribeiro-dos-Santos ${ }^{3}$, Artur Silva ${ }^{1,2}$, Diego Assis das Graças ${ }^{1,2}$, \\ Maria Paula Cruz Schneider ${ }^{1,2}$ and Rafael Azevedo Baraúna ${ }^{1,2 *}$ \\ 1 Laboratory of Genomics and Bioinformatics, Center of Genomics and Systems Biology, Institute of Biological Sciences, \\ Federal University of Pará, Belém, Brazil, ${ }^{2}$ Laboratory of Biological Engineering, Guamá Science and Technology Park, Belém, \\ Brazil, ${ }^{3}$ Laboratory of Medical and Human Genetics, Institute of Biological Sciences, Federal University of Pará, Belém, Brazil
}

The mangrove oysters (Crassostrea gasar) are molluscs native to the Amazonia region and their exploration and farming has increased considerably in recent years. These animals are farmed on beds built in the rivers of the Amazonia estuaries and, therefore, the composition of their microbiome should be directly influenced by environmental conditions. Our work aimed to evaluate the changes in bacterial composition of oyster's microbiota at two different seasons (rainy and dry). For this purpose, we amplified and sequenced the V3-V4 regions of the 16S rRNA gene. Sequencing was performed on the Illumina MiSeq platform. According to the rarefaction curve, the sampling effort was sufficient to describe the bacterial diversity in the samples. Alpha-diversity indexes showed that the bacterial microbiota of oysters is richer during the rainy season. This richness is possibly associated with the diversity at lower taxonomic levels, since the relative abundance of bacterial phyla in the two seasons remained relatively constant. The main phyla found include Firmicutes, Bacteroidetes, Actinobacteria, and Proteobacteria. Similar results were found for the species Crassostrea gigas, Crassostrea sikamea, and Crassostrea corteziensis. Beta-diversity analysis showed that the bacterial composition of oyster's gut microbiota was quite different in the two seasons. Our data demonstrate the close relationship between the environment and the microbiome of these molluscs, reinforcing the need for conservation and sustainable management of estuaries in the Amazonia.

Keywords: mangrove oyster, oyster, oyster microbiota, Amazonia, Crassostrea gasar

\section{INTRODUCTION}

The phylum Mollusca is one of the largest and most important in the animal kingdom. From the six classes that make up the phylum, we can highlight the Bivalvia class, composed of about 7,500 species of soft-bodied animals protected by a shell, which acts as a skeleton for the connection of muscles and protects against predators (Gosling, 2003; Dame, 2011). Oysters are molluscs belonging to the Ostreidae family found in various marine and estuarine environments around the globe (Dame, 2011). 
These animals breathe and feed using their gills, having a food base of microalgae, phytoplankton, microzooplankton, dissolved organic matter, and bacteria (Gosling, 2003).

As filter feeding animals, oysters tend to accumulate a large number of microorganisms present in the water, which can compose their gut microbiota (Harris, 1993; Li et al., 2017). The environment has a fundamental and highly restrictive role in the composition of the gut microbiota of these animals; in addition to that, different species developing in the same environment may have different bacterial populations composing their microbiota due to a difference in the filtration capacity (Trabal et al., 2012; Clerissi et al., 2020). It has been reported that ingested bacteria increase in number in the intestines of some invertebrates. Moreover, the proliferation in the intestine can contribute to digestion, preconditioning the food, thus complementing the enzymes present in the digestive tract (Harris, 1993).

Some phyla have already been identified composing the microbiota of different species of oysters belonging to the Crassostrea genus (King et al., 2012; Chauhan et al., 2014; Fernández et al., 2014; Ossai et al., 2017; Vezzulli et al., 2018). The phylum Proteobacteria is the most abundant, followed by Firmicutes and Bacteroidetes, additionally several other bacterial taxa have already been described composing oysters gut microbiota ( $\mathrm{Li}$ et al., 2017). The microbiota of marine oyster species such as Crassostrea gigas is predominantly composed by marine bacterial genera such as Neptuniibacter, Marinicella, Rhodovulum, and Oceanicola (Fernández et al., 2014). In addition, cultivation site and the oyster's life cycle influence the composition of its microbiota (Fernández et al., 2014). The genera Pseudoalteromonas and Vibrio were the most abundant in the same C. gigas cultivated in the northwestern Italy (Vezzulli et al., 2018).

Prior to the beginning of this research, only studies using classical microbiology methods to assess the gut microbiota of Crassostrea gasar oysters were available (Amadi, 2016; Oliveira et al., 2020). C. gasar is a synonymous species to C. brasiliana, which is found in estuaries along the Brazilian coast (Varela et al., 2007; Melo et al., 2010). This species is vastly used in oyster culture sites in the north of the country for its better tolerance to salinity variation and adaptability to higher water temperature (Funo et al., 2018). Considering that the production and consumption of oysters, as well as other molluscs, has grown expressively in the last 8 years in the northern region of Brazil, assessing these oysters' gut microbiota is important not only for the aquaculture population and consumers but also for the scientific community, given that these oysters have never been studied to such level. The results obtained in this research allowed us to assess the bacterial gut microbiota of C. gasar oysters in two different seasons of the year.

\section{METHOD}

\section{Data Collection}

The sampling took place in two periods, one in the dry season (T1) on October 3rd, 2018 and the other in the rainy season (T2) on April 25th, 2019. Twenty-four oysters were collected, 12 in each period, from a cultivation site during the high tide in the village of Lauro Sodré (0.844866 S 47.884904 W) in Curuçá, in the northeastern region of the state of Pará, Brazil. In this study, two biological triplicates were used, one triplicate for each period. Each replicate had the gastrointestinal content from four oysters giving a final average weight of $10 \mathrm{~g}$. Oysters were kept in a container with ice until being processed on the same day at the Laboratory of Genomics and Bioinformatics of the Federal University of Pará. The oysters were opened with sterile knives in sterile environment and the stomach and intestines were excised with the aid of a scalpel and forceps and preserved in tubes containing RNAlater 1:1 (m/v) (Invitrogen).

\section{Physicochemical Water Analysis}

One liter of water was collected in triplicate at the same site, day and time of the oyster's collection. The water samples were collected in $1 \mathrm{~L}$ polypropylene bottles just above the oyster beds, packed in an isothermal box with ice and sent to the laboratory of the College of Sanitary and Environmental Engineering at the Federal University of Pará. Sampling and analytical methods were performed according to the procedures and recommendations described in the Standard Methods for the Examination of Water and Wastewater (Rice et al., 2012). Physicochemical parameters such as $\mathrm{pH}$, salinity, total suspended solids, turbidity, and apparent color were analyzed by spectrophotometer or multiparametric probe (556 MPS; YSI, USA). Data were compared using one-way ANOVA and Tukey test $(p<0.01)$ in the program BioEstat v.5.0.

\section{DNA Extraction and Amplification}

The DNeasy PowerSoil kit (Qiagen) was used for DNA extraction following the manufacturer's protocol. The concentration and purity of the extracted DNA was assessed using the NanoDrop micro volume spectrophotometer (Thermo Fisher Scientific), all samples showed an absorbance ratio at 260 and $280 \mathrm{~nm} \geq 1.8$. The integrity of the extracted genomic DNA was verified by electrophoresis on $1 \%$ agarose gel. The DNA was amplified by PCR using primers (Forward 5' TCGTC-GGCAGCGTCAGATGTGTATAAGAGACAGCCTACGGGNGGCWGCAG and reverse $\quad 5^{\prime} \quad$ GTCTCGTGGG-CTCGGAGATGTGTATAAGAGACAGGACTACHV-GGGTATCTAATCC) for the variable regions $\mathrm{V} 3$ and $\mathrm{V} 4$ of the $16 \mathrm{~S}$ rRNA gene. The reactions were performed in tubes with $25 \mu \mathrm{L}$ of total volume, denatured for $3 \mathrm{~min}$ at $95^{\circ} \mathrm{C}$ followed by 35 cycles with temperatures of denaturation, annealing and amplification of 95,55 , and $72^{\circ} \mathrm{C}$, respectively, ending with $5 \mathrm{~min}$ of amplification at $72^{\circ} \mathrm{C}$.

\section{Sequencing and Bioinformatics Analysis}

Sequencing library was prepared using the Nextera XT Illumina kit, where sequencing adapters and barcodes were added to the samples. The sequencing was carried out at the Laboratory of Medical and Human Genetics (LGHM) at the Federal University of Pará through the Illumina MiSeq platform. PEAR v.0.9.8 (Zhang et al., 2014) was used to merge the reads. Primers and ambiguous nucleotides were subsequently removed and reads < $225 \mathrm{bp}$ were removed as well as reads with total expected error $>$ 0.5 . Sequences were clustered into Operational Taxonomic Units 
TABLE 1 | Physicochemical parameters.

\begin{tabular}{lccc}
\hline Parameter & T1 & T2 & Fold-change $^{\mathrm{a}}$ \\
\hline Salinity (ppt) & $9.6 \pm 1.4^{\mathrm{c}}$ & $4.43 \pm 0.6^{\mathrm{c}}$ & -2.17 \\
Precipitation (mm) & $\leq 2$ & $5.1-10$ & - \\
$\mathrm{pH}$ & $6.6 \pm 0.2$ & $6.36 \pm 0.15$ & - \\
Total suspended solids $\left(\mathrm{mg} \mathrm{L}^{-1}\right)$ & $27.66 \pm 3.78^{\mathrm{c}}$ & $172.66 \pm 11.01^{\mathrm{c}}$ & 6.24 \\
Turbidity (UNT) & $4.56 \pm 0.41^{\mathrm{c}}$ & $162.66 \pm 30.28^{\mathrm{c}}$ & 35.67 \\
Apparent color $(\mathrm{UC})$ & $10.73 \pm 0.66^{\mathrm{c}}$ & $241 \pm 33.06^{\mathrm{c}}$ & 22.46 \\
Conductivity $\left(\mu \mathrm{S} \mathrm{cm}{ }^{-1}\right)$ & $247.33 \pm 8.5^{\mathrm{c}}$ & $369 \pm 16.52^{\mathrm{c}}$ & 1.49 \\
Total phosphorous $\left(\mathrm{mg} \mathrm{L}^{-1}\right)$ & $1.36 \pm 0.15^{\mathrm{b}, \mathrm{c}}$ & $0.34 \pm 0.12^{\mathrm{b}, \mathrm{c}}$ & -4.0 \\
Ammonium (mg $\left.\mathrm{L}^{-1}\right)$ & $1.03 \pm 0.15^{\mathrm{b}, \mathrm{c}}$ & $1.9 \pm 0.05^{\mathrm{b}, \mathrm{c}}$ & 1.84 \\
Nitrate (mg $\left.\mathrm{L}^{-1}\right)$ & $1.76 \pm 0.2^{\mathrm{b}}$ & $1.23 \pm 0.05^{\mathrm{b}}$ & -1.43 \\
Nitrite $\left(\mathrm{mg} \mathrm{L}^{-1}\right)$ & $0.007 \pm 0.002$ & $0.003 \pm 0.001$ & - \\
Total nitrogen $\left(\mathrm{mg} \mathrm{L}^{-1}\right)$ & $3.23 \pm 0.3$ & $2.4 \pm 0.1$ & - \\
\hline
\end{tabular}

${ }^{a}$ Fold-change was calculated by the ratio of the highest value to the lowest. A negative value indicates a decrease in that parameter in the rainy season (T2).

${ }^{b}$ Values that had not complied with the Brazilian legislation [Conselho Nacional do Meio Ambiente (CONAMA), 2005].

'Statistically significant values $(p<0.01)$

The values are the arithmetic mean and standard deviation of the triplicate for each sample.

(OTUs) based on a dissimilarity of $3 \%$ and chimera sequences were removed with UPARSE pipeline (Edgar, 2013). Taxonomic analysis was performed with USEARCH v.11 comparing with the 16S rRNA database from SILVA v.1.3.2 (Edgar, 2010; Glockner et al., 2017). Functional properties of the microbial communities were predicted using iVikodak (Nagpal et al., 2019).

Statistical analysis was performed with Phyloseq, Vegan, and ggplot packages implemented in R Studio v.1.0.136 (McMurdie and Holmes, 2013). The following alpha-diversity indexes were determined: rarefaction curve, Shannon, Chaol, ACE, and Simpson. Non-Metric Multidimensional Scaling (NMDS) plot was used to compare the bacterial composition of the different seasons.

\section{RESULTS}

The data shown on Table 1 corresponds to the results of the physicochemical analysis for T1 (dry season) and T2 (rainy season). It was possible to notice a considerable variation in total suspended solids, turbidity, apparent color, conductivity, ammonium, total phosphorous, salinity, and precipitation. Such abiotic variations possibly had influenced in the gastrointestinal microbiota composition of oysters from T1 to T2. A low precipitation index $(>2 \mathrm{~mm})$ is expected during the Amazonia summer (T1) (Table 1).

After sequencing and quality filter, each replicate presented $74,234-108,862$ reads with an average size of $300 \mathrm{bp}$, totalling 163 $\mathrm{Mbp}$ of genetic information. According to the rarefaction curve, the sequencing effort was sufficient to describe the bacterial diversity of the samples (Figure 1A). In addition, rarefaction curve shows that the oyster microbiota is richer during the rainy season (Figure 1A), with values close to those of the respective diversity estimators, showing that the depth of the sequencing was sufficient for the description of the bacterial community (Figure 2). The most abundant phyla in the two periods analyzed were Firmicutes, Bacteroidetes, Proteobacteria, and Actinobacteria, in that order (Figure 1B). The recently characterized phylum Elusimicrobia was also found in significant abundance, followed by Tenericutes and Lentisphaerae.

Despite the similar composition in bacterial phyla and classes (Figures 1B,C), the C. gasar microbiota showed significantly higher alpha-diversity indexes (Chao, Ace, and Shannon index) during the rainy season (Figure 2), but similar dominances (Simpson index). This result indicates that the change in the bacterial diversity occurs at lower taxonomic levels, since the relative abundance of bacterial phyla in the two seasons remained relatively constant (Figure 1B). Indeed, the heatmap in Figure 3A shows that some bacterial classes are abundant only in the rainy season such as Gammaproteobacteria, Betaproteobacteria, Zetaproteobacteria, Thermodesulfobacteria, Flavobacteria, Endomicrobia, among others. These differences are even more pronounced at the family level (Supplementary Figure 1). Epsilonproteobacteria was the most abundant Proteobacteria class during the dry season (Figure 3A). At the genus level, several taxa commonly associated with the gut microbiota of animals were found enriched in the oysters' gut during the dry season such as Escherichia, Shigella, Bifidobacterium, Lactobacillus, Prevotella, and Ruminococcus (Supplementary Figure 2). Flavonoiddegrading bacteria such as Flavonifractor were abundant during the rainy season (Supplementary Figure 2) (Ulbrich et al., 2015). As expected, some environmental genera were also found in the oysters' gut microbiota such as Telmatospirilum and Desulfonatrobacter (rainy season), and Magnetococcus and Anaerosalibacter (dry season). Comparing samples using Non-Metric Multidimensional Scaling (NMDS) plot it was evident that the bacterial diversity of oysters' gut microbiome was different in the two Amazonia seasons (Figure 3B).

Supplementary Figure 4 shows the abundant functions of the microbial communities predicted by iVikodak. Basic functional properties such as carbohydrate and amino acid metabolism, and DNA replication and repair were most abundant during rainy season. An important biochemical pathway for the hostmicrobiome interaction such as the metabolism of cofactors and vitamins was among the most abundant in the samples (Supplementary Figure 4).

\section{DISCUSSION}

During the dry season the sampling site presented a high salinity and low amount of total suspended solids (Table 1). In both periods, samples were considered as brackish water according to the Brazilian legislation [(Conselho Nacional do Meio Ambiente (CONAMA), 2005)]. Physicochemical parameters that had not complied with the Brazilian legislation were total phosphorous, nitrate and ammonium. Nitrate concentration did not change significantly between seasons (Table 1). The concentration of ammonium however was higher during the rainy season, possibly due to the carrying of organic matter from the soil to the 

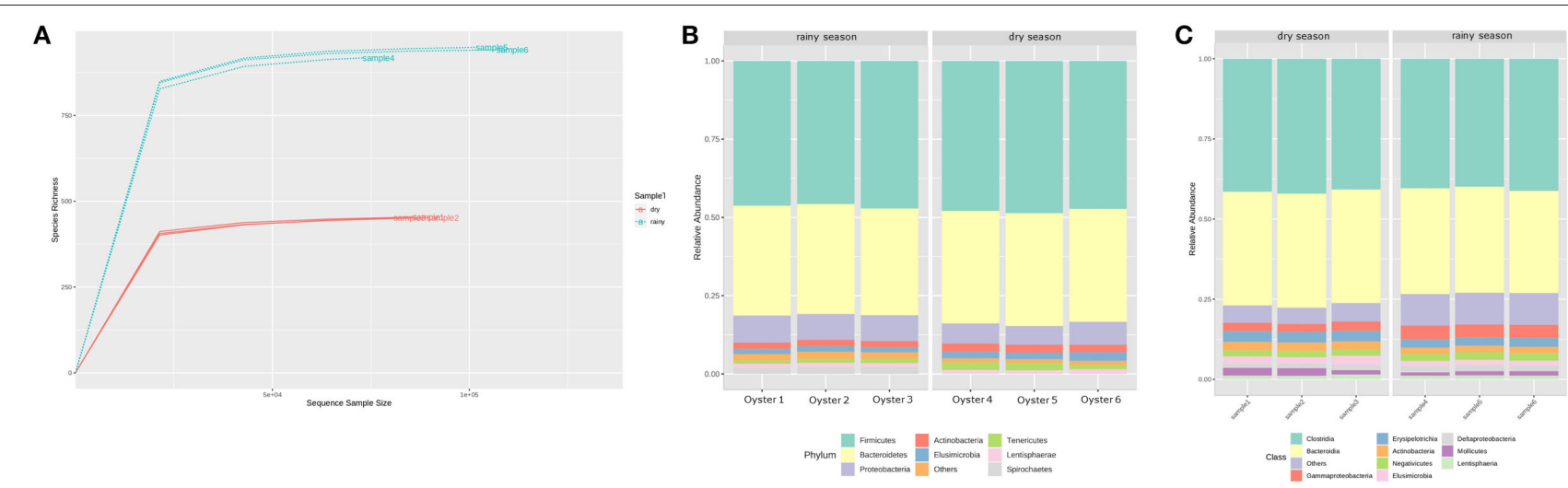

FIGURE 1 | (A) Rarefaction curve of estimated OTUs in the 16S rDNA libraries. Samples from the rainy season (blue dotted lines) are notoriously richer compared to the dry season (red dotted lines). (B) Histogram of bacterial phyla diversity found in each replicate sequenced. Firmicutes, Bacteroidetes, Proteobacteria, and Actinobacteria were the most abundant phyla. No considerable difference can be noted in the relative abundance of these phyla. (C) Histogram of bacterial classes.
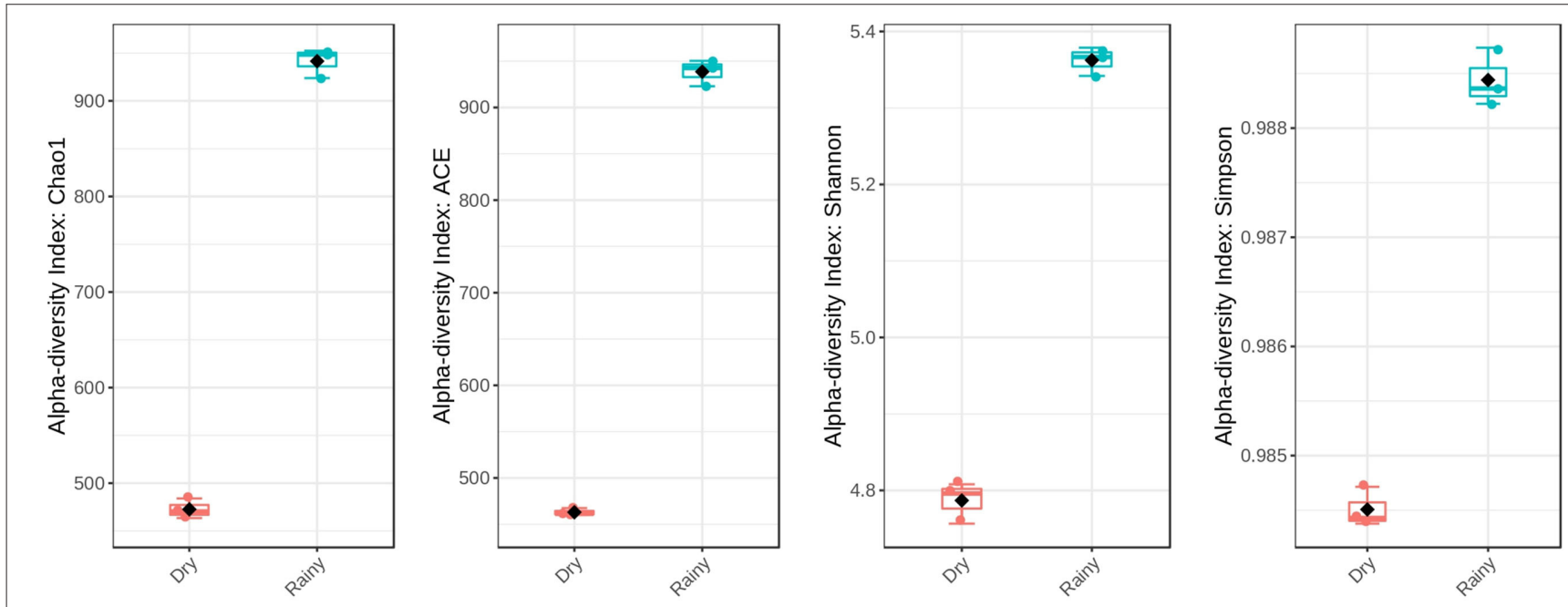

FIGURE 2 | Alpha-diversity indexes comparing the two seasons analyzed. In all cases, the rainy season samples showed higher levels of diversity.

estuary by the rains. Ammonia is a common product of biological degradation. The high temperature of the region and the near neutral water $\mathrm{pH}$ found are important factors that favor biocalcification and shell formation (Waldbusser et al., 2011). Salinity is also an important factor in oyster farming. Sampling point showed 9.6 and $4.43 \mathrm{ppt}$ in the dry and rainy seasons, respectively. These low salinity values can be explained by the distance from the ocean. The village of Lauro Sodré is the most distant of all oyster farming villages on the Amazonia coast. Interestingly, it has the largest natural nursery system of oyster seeds of the region (Sampaio et al., 2019).

Firmicutes, Bacteroidetes, Proteobacteria, and Actinobacteria were the most abundant phyla in the two seasons analyzed (Figure 1B). The same phyla were described as the most abundant in the microbiota of the Pacific oysters Crassostrea sikamea and Crassostrea gigas, and the Mexican oyster Crassostrea corteziensis (Fernández et al., 2014). However, unlike our findings, Fernández et al. (2014) observed Proteobacteria as most abundant phylum in the Pacific and Mexican oysters when analyzing only the resident microbiota. A deeper investigation about the resident and transient microbiota of mangrove oysters should be performed to better elucidate microbial dynamics in such environments.

Regarding other species, the bacterial microbiota of Crassostrea viriginca is mainly dominated by the phylum Cyanobacteria (Chauhan et al., 2014), for which in our analysis, the number of reads mapped to the Cyanobacteria phylum was insignificant. Interestingly, Chauhan et al. (2014) identified Cyanobacteria spp. as the dominant taxon in the water column of the C. virginica farming site, which indicates an intrinsic 

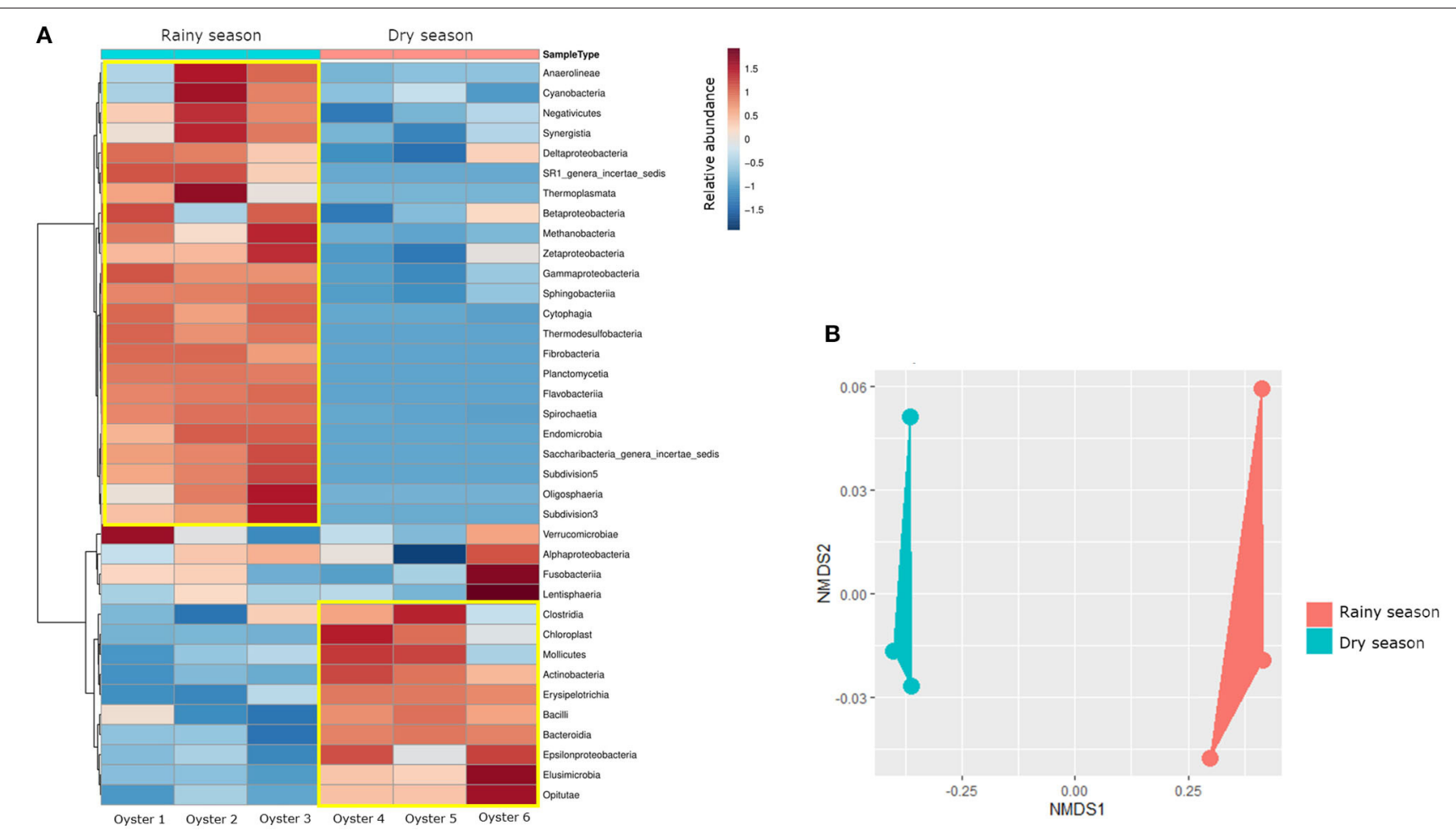

FIGURE 3 | (A) Heatmap comparing the relative abundance of bacterial classes. The yellow square highlights the classes with higher relative abundance in each season. The dendogram on the left side reinforces the difference in the composition of bacterial classes in each season. (B) Non-Metric Multidimensional Scaling (NMDS) plot comparing the bacterial composition of samples. The samples were grouped according to the Amazonia seasons.

connection between the oyster microbiome and the aquatic environment. C. virginica grows in the salty waters of the Atlantic coast while C. gasar grows in the brackish waters of the Amazonia estuaries. The difference between these environments is probably an important factor that contributes to the difference between the microbiota of these two oyster species.

Beta-diversity analysis demonstrated that there is a change in the bacterial composition of the oyster microbiota comparing the dry and rainy seasons (Figure 3B). Zurel et al. (2011) also found significant seasonal variation in bacterial populations in the gill of Indo-Pacific oyster Chama pacifica. Other biotic and abiotic factors have already been described influencing the composition of bacterial microbiota of bivalve molluscs. Offret et al. (2020) showed that C. gigas modifies its bacterial microbiota according to the farming position in an intertidal zone. Bernal et al. (2016) showed that farming of C. sikamea with potentially probiotic bacterial genus, such as Streptomyces, leads to a change in the oyster's microbiota. In our data, relevant changes in terms of abundance were observed at the genus level (Supplementary Figure 2). The metabolism of carbohydrates, fatty acids, amino acids and even antibiotic resistance genes were more abundant in the rainy season (Supplementary Figures 4, 5), when the bacterial microbiota was richer (Figure 2). The inference of metabolism based on 16S sequencing has already been used to compare the gut microbial communities of human populations living in urban and tribal areas (Singh et al., 2019), landfill sites with different characteristics (Thakur et al., 2020), and polystyrene-degrading biofilms cultivated under different conditions (Tourova et al., 2020).

The sequencing of the 16S rRNA gene was previously used to assess bacterial diversity in C. gasar (Ostrensky et al., 2018). However, the authors evaluated the differences in the composition of bacterial microbiota of living oysters stored in two different conditions, and found that oysters stored exposed to the air at a temperature of $5-25^{\circ} \mathrm{C}$ have a less diverse bacterial microbiota and a smaller number of potentially pathogenic taxa (Ostrensky et al., 2018).

To the best of our knowledge, this is the first study to evaluate the bacterial microbiota of C. gasar farmed in their natural habitat. The sustainable management of mangrove oysters is extremely important for Amazonia. Our research is important for the comprehension of the relationship between the environment and the oyster's microbiome, which appears to be influenced by biotic and abiotic factors and may have an important influence in farming management and human consumption.

\section{DATA AVAILABILITY STATEMENT}

The datasets presented in this study can be found in online repositories. The names of the repository/repositories and 
accession number(s) can be found below: https://www.ncbi.nlm. nih.gov/genbank/, PRJNA661079.

\section{AUTHOR CONTRIBUTIONS}

MC and RB: collected the samples, analyzed and interpreted the data, and wrote the manuscript. SC and DG: contributed to the bioinformatics analyses. APS and ÂR-d-S: contributed to the sequencing analysis. AS, DG, MS, and RB: conceived the study. All authors contributed to the article and approved the submitted version.

\section{REFERENCES}

Amadi, L. O. (2016). Mortality and microbial diversity of raw, processed and storage of mangrove oysters (Crassostrea gasar). Int. Res. J. Pub. Environ. Health. 3, 7-13. doi: 10.15739/irjpeh.16.002

Bernal, M. G., Fernández, N. T., Lastra, P. E. S., Marrero, R. M., and MazónSuástegui, J. M. (2016). Streptomyces effect on the bacterial microbiota associated to Crassostrea sikamea oyster. J. Appl. Microbiol. 122, 601-614. doi: 10.1111 /jam. 13382

Chauhan, A., Wafula, D., Lewis, D. E., and Pathak, A. (2014). Metagenomic assessment of the eastern oyster-associated microbiota. Genome Announc. 2, e01083-e01014. doi: 10.1128/genomeA.01083-14

Clerissi, C., Lorgeril, J., Petton, B., Lucasson, A., Escoubas, J. M., Gueguen, Y., et al. (2020). Diversity and stability of microbiota are key factors associated to healthy and diseased Crassostrea gigas oysters. Front. Microbiol. 11:311. doi: $10.3389 /$ fmicb.2020.00311

Conselho Nacional do Meio Ambiente (CONAMA) (2005). Resolução CONAMA $N^{\circ}$ 357/2005. Brasília: Diário Oficial da República Federativa do Brasil.

Dame, R. (2011). Ecology of Marine Bivalves: An ecosystem Approach. Boca Raton, FL: CRC Press.

Edgar, R. C. (2010). Search and clustering orders of magnitude faster than BLAST. Bioinformatics 26, 2460-2461. doi: 10.1093/bioinformatics/btq461

Edgar, R. C. (2013). UPARSE: highly accurate OTU sequences from microbial amplicon reads. Nat. Methods 10, 996-998. doi: 10.1038/nmeth.2604

Fernández, N. T., Mazón-Suástegui, J. M., Vázquez-Juárez, R., Ascencio-Valle, F., and Romero, J. (2014). Changes in the composition and diversity of the bacterial microbiota associated with oysters (Crassostrea corteziensis, Crassostrea gigas and Crassostrea sikamea) during commercial production. FEMS Microbiol. Ecol. 88, 69-83. doi: 10.1111/1574-6941.12270

Funo, I. C. S. A., Antonio, I. G., Marinho, Y. F., and Gálvez, A. O. (2018). Influence of salinity on survival and growth of Crassostrea gasar. Boletim Inst. Pesca 41, 837-847. Available online at: https://www.pesca.sp.gov.br/boletim/index. $\mathrm{php} / \mathrm{bip} / \mathrm{article} / \mathrm{view} / 1076$

Glockner, F. O., Yilmaz, P., Quast, C., Gerken, J., Beccati, A., Ciuprina, A., et al. (2017). 25 years of serving the community with ribosomal RNA gene reference databases and tools. J. Biotechnol. 261, 169-176. doi: $10.1016 /$ j.jbiotec.2017.06.1198

Gosling, E. (2003). Bivalve Molluscs: Biology, Ecology and Culture. Oxford: Foshing News Books. doi: 10.1002/9780470995532

Harris, J. M. (1993). The presence, nature, and role of gut microflora in aquatic invertebrates: a synthesis. Microb. Ecol. 25, 195-231. doi: 10.1007/BF00171889

King, G. M., Judd, C., Kuske, C. R., and Smith, C. (2012). Analysis of stomach and gut microbiomes of the eastern oyster (Crassostrea virginica) from coastal Louisiana, USA. PLoS ONE 12:e51475. doi: 10.1371/journal.pone.0051475

Li, Z., Nicolae, V. V., Akileh, R., and Liu, T. (2017). A brief review of oyster-associated microbiota. Microbiol. Res. J. Int. 20, 1-14. doi: 10.9734/MRJI/2017/33842

McMurdie, P. J., and Holmes, S. (2013). Phyloseq: an R package for reproducible inter-active analysis and graphics of microbiome census data. PLOS ONE 8:e61217. doi: 10.1371/journal.pone.0061217

Melo, A. G. C., Varela, E. S., Beasley, C. R., Schneider, H., Sampaio, I., Gaffney, P. M., et al. (2010). Molecular identification, phylogeny and geographic

\section{FUNDING}

This work was supported by the Coordenação de Aperfeiçoamento de Pessoal de Nível Superior (CAPES) and Fundação Amazônia de Amparo a Estudos e Pesquisas (FAPESPA) (Grant Number 2155/2017).

\section{SUPPLEMENTARY MATERIAL}

The Supplementary Material for this article can be found online at: https://www.frontiersin.org/articles/10.3389/fgene. 2020.602608/full\#supplementary-material

distribution of Brazilian mangrove oysters (Crassostrea). Genet. Mol. Biol. 33, 564-572. doi: 10.1590/S1415-47572010000300030

Nagpal, S., Haque, M. M., Singh, R., and Mande, S. S. (2019). iVikodak - A platform and standard workflow for inferring, analyzing, comparing, and visualizing the functional potential of microbial communities. Front. Microbiol. 9:3336. doi: 10.3389/fmicb.2018.03336

Offret, C., Paulino, S., Gauthier, O., Château, K., Bidault, A., Corporeau, C., et al. (2020). The marine intertidal zone shapes oyster and clam digestive bacterial microbiota. FEMS Microbiol. Ecol. 96:fiaa078. doi: 10.1093/femsec/ fiaa078

Oliveira, A. M. S., Baraúna, R. A., Marcon, D. J., Lago, L. A. B., Silva, A., Lusio, J., et al. (2020). Occurrence, antibiotic-resistance and virulence of E. coli strains isolated from mangrove oysters (Crassostrea gasar) farmed in estuaries of Amazonia. Mar. Pollut. Bull. 157:111302. doi: 10.1016/j.marpolbul.2020.111302

Ossai, S., Ramachandran, P., Ottesen, A., Reed, E., DePaola, A., and Parveen, S. (2017). Microbiomes of American oysters (Crassostrea virginica) harvested from two sites in the Chesapeake Bay. Genome Announc. 5, e00729-e00717. doi: 10.1128/genomeA.00729-17

Ostrensky, A., Horodesky, A., Faoro, H., Balsanelli, E., Sfeir, M. Z. T., Cozer, N., et al. (2018). Metagenomic evaluation of the effects of storage conditions on the bacterial microbiota of oysters Crassostrea gasar (Adanson, 1757). J. Appl. Microbiol. 125, 1435-1443. doi: 10.1111/jam.14045

Rice, E. W., Baird, R. B., Eaton, A. D., and Clesceri, L. S. (2012). Standard Methods for the Examination of Water and Wastewater. Washington, DC: APHA.

Sampaio, D. S., Tagliaro, C. H., Schneider, H., and Beasley, C. R. (2019). Oyster culture on the Amazon mangrove coast: asymmetries and advances in an emerging sector. Rev. Aquac. 11, 88-104. doi: 10.1111/raq.12227

Singh, R., Haque, M. M., and Mande, S. S. (2019). Lifestyle-induced microbial gradients: an Indian perspective. Front. Microbiol. 10:2874. doi: 10.3389/fmicb.2019.02874

Thakur, K., Chownk, M., Kumar, V., Purohit, A., Vashisht, A., Kumar, V., et al. (2020). Bioprospecting potential of microbial communities in solid waste landfills for novel enzymes through metagenomic approach. World J. Microbiol. Biotechnol. 36, 34. doi: 10.1007/s11274-020-02812-7

Tourova, T., Sokolova, D., Nazina, T., Grouzdev, D., Kurshev, E., and Laptev, A. (2020). Biodiversity of microorganisms colonizing the surface of polystyrene samples exposed to different aqueous environments. Sustainability 12:3624. doi: $10.3390 /$ su12093624

Trabal, N., Mazón-Suástegui, J. M., Vázquez-Juárez, R., Asencio-Valle, F., MoralesBojórquez, E., and Romero, J. (2012). Molecular analysis of bacterial microbiota associated with oysters (Crassostrea gigas and Crassostrea corteziensis) in different growth phases at two cultivation sites. Microb. Ecol. 65, 555-569. doi: 10.1007/s00248-012-0039-5

Ulbrich, K., Reichardt, N., Braune, A., Kroh, L. W., Blaut, M., and Rohn, S. (2015). The microbial degradation of onion flavonol glucosides and their roasting products by the human gut bacteria Eubacterium ramulus and Flavonifractor plautii. Food Res. Int. 67, 349-355. doi: 10.1016/j.foodres.2014. 11.051

Varela, E. S., Beasley, C. R., Schneider, H., Sampaio, I., Marques-Silva, N. S., and Tagliaro, C. H. (2007). Molecular phylogeny of mangrove oysters (Crassostrea) from Brazil. J. Mollus. Stud. 73, 229-234. doi: 10.1093/mollus/ eym018 
Vezzulli, L., Stagnaro, L., Grande, C., Tassistro, G., Canesi, L., and Pruzzo, C. (2018). Comparative $16 \mathrm{~S}$ rDNA gene-based microbiota profiles of the Pacific oyster (Crassostrea gigas) and the Mediterranean mussel (Mytilus galloprovincialis) from a shellfish farm (Ligurian Sea, Italy). Microb. Ecol. 75, 495-504. doi: 10.1007/s00248-017-1051-6

Waldbusser, G. G., Voigt, E. P., Bergschneider, H., Green, M. A., and Newell, R. I. E. (2011). Biocalcification in the eastern oyster (Crassostrea virginica) in relation to long-term trends in Chesapeake Bay pH. Estuar. Coasts 34, 221-231. doi: 10.1007/s12237-010-9307-0

Zhang, J., Kobert, K., Flouri, T., and Stamatakis, A. (2014). Pear: a fast and accurate Illumina paired-end read merger. Bioinformatics 30, 614-620. doi: 10.1093/bioinformatics/btt593

Zurel, D., Benayahu, Y., Or, A., Kovacs, A., and Gophna, U. (2011). Composition and dynamics of the gill microbiota of an invasive Indo-Pacificoyster in the eastern Mediterranean Sea. Environ. Microbiol. 13:1467-1476. doi: 10.1111/j.1462-2920.2011.02448.x

Conflict of Interest: The authors declare that the research was conducted in the absence of any commercial or financial relationships that could be construed as a potential conflict of interest.

Copyright (C) 2021 Conceição, Costa, Schaan, Ribeiro-dos-Santos, Silva, das Graças, Schneider and Baraúna. This is an open-access article distributed under the terms of the Creative Commons Attribution License (CC BY). The use, distribution or reproduction in other forums is permitted, provided the original author(s) and the copyright owner(s) are credited and that the original publication in this journal is cited, in accordance with accepted academic practice. No use, distribution or reproduction is permitted which does not comply with these terms. 